\title{
The Forum Community, the Connectivist Element of an xMOOC
}

\author{
Magali Dubosson ${ }^{1, *}$, Sabine Emad ${ }^{2}$ \\ ${ }^{1}$ School of Management Fribourg, University of Applied Sciences Western Switzerland, Switzerland \\ ${ }^{2}$ School of Management Geneva, University of Applied Sciences Western Switzerland, Switzerland
}

Copyright $(\mathcal{C} 2015$ by authors, all rights reserved. Authors agree that this article remains permanently open access under the terms of the Creative Commons Attribution License 4.0 International License

\begin{abstract}
One of the fastest growing approaches to teaching and learning in the new digital paradigm is the use of Massive Open Online Courses (MOOCs). They are categorised either as cMOOCs following a connectivist approach, or as XMOOCs based on behaviourist principles. However, in xMOOC environments, forums may play a real connectivist role if they are functioning as a community. This paper builds on the criteria of Herring (2004) in order to determine the existence and dynamics of a community. Forum participants, in a connectivist approach, create knowledge together by requesting help, answering questions, discussing concepts and techniques, and suggesting applications and additional learning material. This research questions the existence of a clear distinction between cMOOCs and xMOOCs. It was also observed that gender roles in STEM classes are replicated online. Online teaching nowadays is no longer based on one-way processes but includes users in multi-way processes. These dynamics may be effective in ensuring a strong and well-functioning learning community.
\end{abstract}

Keywords MOOCs, Forum, Gender, Community, Learning dynamics. A.m. General Literature: Miscellaneous

\section{Introduction}

Massive Open Online Courses (MOOCs) allow huge numbers of students to participate in distance learning whenever, wherever and as intensively as they wish. The first MOOC was launched in Canada, in the province of Manitoba in September 2008 [1]. It drew more than 2,200 students who participated in the course without charge [2]. Since then, the number of MOOCs has grown substantially. The number of MOOCs' participants has recently soared with the creation of platforms such as Udacity, Coursera or EDx, where the world's most renowned universities offer courses in areas as diverse as programming languages, business, science or arts.
The problems that are often associated with online learning are the limited quality of resources and materials supporting the learning experience and the lack of human to human interaction $[3,4]$. These shortcomings might be compensated for by the opportunities offered by highly active forums which are considered by some researchers as a 'tremendous educational resource to participants' [4]. Forums might contribute to the emerging collaborative learning phenomenon that can be defined as 'learning which arises out of the interaction between a number of people and resources, in which the learners organise and determine both the process and to some extent their learning objectives, both of which are unpredictable' [5]. Learning might be even more effective in the absence of a teacher as it encourages students to adopt independent learning and to explore more bravely [6]. Today's challenges 'lie in the real transition to a less tutor-led approach to learning'[7]. Content will not be delivered to learners but co-constructed with them [7]. It corresponds to a connectivist approach aiming at a more inclusive, flexible and adaptable learning environment. [5]. This learning could emerge from forums that provide interesting patterns of interaction, where students engage with the course material and with each other [4].

Teachers might be reluctant to change to a more connectivist approach where an important part of the course is co-constructed among students [6]. In a traditional classroom, a teacher can control most of the content and interactions as this approach is based on the transmission of structured information from the professor to the class. The instructor provides shape and direction to the learning experience [2]. On the contrary, in MOOC forums for example, participants have the possibility not only to ask questions, but also to answer promptly questions asked by fellow participants, to bring some new material or to raise new issues related to the course. In this changing environment, it becomes crucial for instructors to understand MOOC forums and their dynamics in order to be better able to deal with some loss of control and capitalise on participant-generated content in order to build a more inclusive, flexible and adaptable learning environment. 
This paper analyses the forum related to a specific MOOC course in order to better understand the patterns of interactions among learners and instructors. We also wanted to discover what role this educational resource played in fostering social learning and community participation. We chose to study a science course in order to find out how people perceive challenging tasks and how they interact to understand technical and mathematical topics. In particular, we wanted to find out whether there were any gender differences in students' attitudes and behaviours.

\section{Literature Review}

MOOCs are defined as large-scale online courses due to their high enrolment numbers in the range of a few thousand to more than 100,000 registrants $[3,8]$. A MOOC integrates 'the connectivity of social networking, the facilitation of an acknowledged expert in a field of study, and a collection of freely accessible online resources [...] A MOOC builds on the active engagement of large number of 'students' who self-organise their participation according to learning goals, prior knowledge and skills, and common interests. Although it may share some of the conventions of an ordinary course, such as a predefined timeline and weekly topics for consideration, a MOOC generally carries no fees, and no prerequisites other than Internet access and interest' [8].

\section{Individualistic vs Connectivist MOOCs}

MOOCs have been categorised either as cMOOCs or as xMOOCs. xMOOCs are offered in a traditional university model where the teacher is the expert and the learners are knowledge consumers [2]. They display a more individualistic approach to learning [9] and are based on behaviourist types of pedagogy [10,11]. Knowledge is transferred through a hub-and-spoke model with the faculty at the centre and the learners as duplicators of knowledge [2]. Curricula are structured around weekly lecture videos, computer-graded assignments and quizzes. Additionally, students can share thoughts and ask questions in the related forums. Usually, xMOOCs are offered on a single platform combining a limited number of teaching tools. The first xMOOC was launched by Stanford University in 2011 with its artificial intelligence course. This is the model chosen by the elite US institutions [12].

By contrast, cMOOCs are based on a connectivist approach as they are grounded on the interactions among learners [13]. Social meaning is created by learners' engagement and participation [3]. The knowledge is co-generated by students through the creation of artifacts [2]. The curriculum is not predefined as part of the course design but is built on the contribution of learners (e.g. ideas, links, content, summaries and tools) [14]. The first cMOOC, designed by Siemens and Downes, was made available through RSS (i.e. Really Simple Syndication) feeds, and learners could participate with the tool they favoured (e.g. Moodle, blog posts, Second Life or synchronous online meetings) [12]. According to Bates [10], cMOOCs provide students with the possibility to feel treated as an individual, as they are mainly supported by some 'form of discussion, encouragement, and an understanding of an individual student's needs'.

For some researchers, the distinction between cMOOC and $\mathrm{xMOOC}$ is not so clear and there is still a gap in the literature in defining the types of MOOCs [15]. On the contrary, others maintain that 'they are so distinct in pedagogy that it is confusing to designate them by the same term' $[12,16]$. According to Siemens [17], 'cMOOCs focus on knowledge creation and generation whereas xMOOCs focus on knowledge duplication'.

Table 1. Comparison of cMOOCs and xMOOCs

\begin{tabular}{|c|c|c|}
\hline & cMOOC & XMOOC \\
\hline Focus & $\begin{array}{c}\text { Network } \\
\text { (connections) }\end{array}$ & Content \\
\hline Pedagogy & $\begin{array}{l}\text { Collaborative } \\
\text { production }\end{array}$ & $\begin{array}{l}\text { Transfer (ex-cathedra } \\
\text { teaching) }\end{array}$ \\
\hline $\begin{array}{l}\text { Pedagogical } \\
\text { model }\end{array}$ & Connectivism & Behaviourism \\
\hline Teacher & Facilitator & Expert \\
\hline Learner & $\begin{array}{l}\text { Knowledge } \\
\text { co-creator }\end{array}$ & $\begin{array}{c}\text { Knowledge consumer / } \\
\text { replicator }\end{array}$ \\
\hline Curriculum & Open / adaptive & Predefined / structured \\
\hline Assignment & Artifacts & $\begin{array}{l}\text { Computer-graded "drill } \\
\text { and grill" }\end{array}$ \\
\hline Feedback & $\begin{array}{l}\text { Direct feedback- } \\
\text { peers respond to } \\
\text { questions, discuss } \\
\text { new issues and } \\
\text { question the } \\
\text { relevance of content }\end{array}$ & $\begin{array}{l}\text { No direct feedback - } \\
\text { instructors and teaching } \\
\text { staff may rarely respond } \\
\text { to questions in forums }\end{array}$ \\
\hline Dynamics & $\begin{array}{c}\text { Learn in and from a } \\
\text { network }\end{array}$ & Learn from the teacher \\
\hline $\begin{array}{l}\text { Students' } \\
\text { motivation }\end{array}$ & $\begin{array}{l}\text { Self- and highly } \\
\text { motivated students } \\
\text { regarding a particular } \\
\text { topic }\end{array}$ & $\begin{array}{l}\text { Access to very } \\
\text { expensive elite } \\
\text { education for free }\end{array}$ \\
\hline Tools & $\begin{array}{l}\text { Students can choose } \\
\text { among various tools }\end{array}$ & Single platform \\
\hline
\end{tabular}

In individualistic cultures, the needs, values, and goals of the individual take precedence over the needs, values, and goals of the group. On the contrary, in collectivist cultures the needs, values, and goals of the group take precedence over the individual ones $[18,19]$. When studying online, the group of learners gets together and meets on the forums. Therefore, collectivist needs, values and goals would be more likely met through the use of forums. According to Herring [20], building a virtual community through the gathering of learners is possible, but not all online groups constitute virtual communities. An early definition describes virtual communities as 'social aggregations that emerge from the Net when enough people carry on public discussions long enough, with sufficient human feeling, to form webs of personal relationships in cyberspace'[21]. A virtual community was later defined as 'a group of people who interact in a virtual environment with a purpose, supported by technology and guided by norms and policies' [22]. In online learning communities, students work together and 
expand their knowledge base collaboratively [23]. More specifically, virtual communities have to meet six sets of criteria: (1) active, self-sustaining participation, and a core of regular participants (2) shared history, purpose, culture, norms and values (3) solidarity, support, reciprocity (4) criticism, conflict, means of conflict resolution (5) self-awareness of group as an entity apart from other groups (6) emergence of roles, hierarchy, governance, rituals [20]. To this list of characteristics, Preece added the presence of computer systems, operating to support and mediate all these functions [24]. Herring's framework will be used in our analysis in order to determine whether there was a strong community and whether participants could feel it.

\section{Forum dynamics and sense of community}

Building a virtual community and generating a strong sense of belonging might be crucial for an online learning experience. Online class participation and collaborative learning are essential to student success and satisfaction [25]. According to Rovai [26], 'strong feelings of community may not only increase persistence in courses, but may also increase the flow of information among all learners, availability of support, commitment to group goals, cooperation among members and satisfaction with group efforts'. Moreover, interactions among peers, rather than interactions with instructors, are linked to higher satisfaction, more high-level knowledge discussions and a potentially stronger sense of community [27]. Student participation may increase when the discussions are not led by instructors [28, 29]. Previous research also indicates that a small number of contributors can be the authors of an overwhelming percentage of posts [30]

Social interaction is based on the ability of people to project their personalities into the group and to develop a sense of community [31], defined as feelings of connectedness among participants and as a commonality of learning expectations and goals [32]. Students develop a strong sense of community where group norms, social identity, attitudes and anticipated emotions contribute to the development of behavioural desires that in turn influence member contribution behaviour within a larger community [33]. Tsai and Bagozzi [34], for example, explained that the development of group-level influences requires three bases: 'social compliance (normative responsiveness based on the need for approval), identification (members' identification with other participants in the virtual community) and internationalisation (congruence of one's values and goals with group members).

\section{Learning from the network and academic performance}

The variety of posts in a forum reflects the diversity of the student body. Threads cover very different topics such as course content, questions and their answers, and organisational issues [35]. But this huge diversity may cause some trouble for participants. The number of threads can become overwhelming and generate a feeling of loss for participants who feel less confident to voice their opinions [36]. Therefore, there should be a trade-off between having enough participants for an active forum and having too much participation which makes participants feel overwhelmed [32]. Large volumes of data generated in forums make it difficult and challenging to be up-to-date with the content [15].

There is no consensus about the link between online social interaction and academic performance. Some studies observed that more peer interactions generate higher academic performance $[37,38]$. On the contrary, another study concluded that students with higher grades tend to read less of the forum content than those with lower grades [35]. The same study also showed that students who handed in the lowest number of assignments used the forum to find study partners and used non-English words.

MOOCs experience very high drop-out rates of about $90 \%$ on average $[39,40]$, with the highest completion rate observed at $19.2 \%$ [25]. There is no evidence that social interaction is linked to higher completion rates. Previous studies indicate that the activity in forums drops considerably as a course progresses [41]. However, forum content might help explain the reasons for these drop-outs. The analysis of forum content indicated that drop-out rates would be minimised if online courses were moderately difficult, did not require a heavy workload and were spread over less than eight weeks [42].

\section{Gender differences in STEM Courses}

Research has shown that, in traditional learning settings, men were more interested in and inclined to study STEM (Science, Technology, Engineering, and Mathematics) fields $[43,44]$. Studies observed that male students received more attention than female students, were more frequently requested to answer questions, were given greater freedom to call out answers and received more positive feedback [45-48].

A study based on 21 graduate online students found that there were no significant gender differences in discourse styles and participation [49]. However, several studies conducted in online environments noted that men and women display differences in their communication mode and behaviour in their online learning experience [50-52]. A study conducted in 4 MOOC environments (artificial intelligence, introductory computer science, chemistry and statistics for public health courses) confirmed previous research, observing that there were around seven times more men than women enrolled online [53], the largest gender disparity being in the two computer science courses. In two classes (statistics and computer science), men performed fewer "back jumps" (the number of times a student navigated backwards from a learning sequence to another one released earlier) than women [54]. In terms of performance, it was observed that women performed worse than equally skilled men on more challenging or frustrating quantitative tasks [ 53 , 55].

\section{Method}

Field study description 
This study comprises a thorough analysis of the forum content of a MOOC related to a STEM course offered by one of the top MOOC platforms. Part of the requirements for this class included the use of algebra and complex models; however, it did not require high-level mathematics or computing skills. When registering, students were advised to be comfortable with basic algebra and to understand the use of derivative algebra.

This course was taught over ten weeks. Each week, four to seven video lectures, each 5 to 19 minutes long, were made available online. The class was offered by an American university and taught by an English mother-tongue professor. Students could choose between English or Portuguese subtitles. The understanding and assimilation of the course was evaluated every week through quizzes and, at the end of the class, through a final examination using the same format as the weekly quizzes. Upon completing the course requirements, participants could obtain a free statement of accomplishment or choose to pay for a course certificate (including a process to confirm student identity throughout the course).

Two months after the end of the class, the content of the course related web forum was collected in order to analyse its make-up, to define the role of the forum and to obtain insights about the interactions among course participants. The comments of the most active threads were copied and pasted in a Word document for analysis. For this class, there were 3509 posts in total, spread over 625 threads (an average of 5.6 posts per thread). As we wanted to focus on the most significant interactions among participants and the most impactful contributions, we chose to select the threads according to their number of posts (minimum ten posts) and of views (minimum 100 views). Posts indicate the number of interactions within a thread. Views show the number of times participants read the content. We assumed that some participants would only read the content if they found it relevant to, or enriching for their learning experience. We selected 2,219 posts $(63.2 \%$ of the total number of posts) representing the most active threads. There was a total of 656 A4 pages, written in 12-point Times New Roman font with very few pictures or graphs.

Analysis procedure

Our study is based on the observation of textual discourse. In this case, we analysed the written communication and interactions occurring among the participants in the online environment of the MOOC. Once the data were collected, they were read, coded and interpreted. Firstly, a list of codes related to peer interaction was constructed based on a former exploratory study concerning MOOCs [56]. A preliminary analysis of 400 posts was then performed, to refine these codes. This preliminary analysis, supported by our literature review, resulted in 35 codes that were then used for the analysis of the complete data corpus. All the collected data were tagged and coded using the RQDA software and analysed using the text analysis software, Tropes. Both software are open-source. This procedure allowed us to count the most frequent codes, words and the main substantives grouped into themes. We conducted a member validation for these two steps to ensure higher reliability of our findings.

This procedure followed the principles of netnography methodology. Netnography is used 'to understand virtual communities in the same way that anthropologists seek to understand cultures, norms and practices of face-to-face communities' [57]. It is, therefore, perfectly suited to study the virtual communities of MOOCs, and can be conducted entirely unobtrusively [58]. In order to avoid introducing any sort of bias or potential 'researcher effect' in the social dynamics among participants [59], researchers did not participate in the forum. This analysis captures individuals and groups in their natural online setting and can therefore be considered as a naturalistic inquiry field approach, or non-participant ethnographic observation $[60,61]$.

It is worth mentioning that netnography uses only the information that is publicly available in online forums [58]. In our research, the course and forum data were publicly available to any person registered to the course. The MOOC website also mentions under 'confidentiality' that students must 'keep in mind that information they post or make available in forums will be publicly available. Accordingly, they should be careful when posting any personal or sensitive information'. The researchers adopted an ethical posture by using public information and by ensuring that no harm would come to the subjects of the study [62]. However, since analysing a virtual "classroom" without informing the participants or the authors of the course might pose an ethical dilemma, it was decided to collect the data only after the course had ended and to treat data confidentially and anonymously. The title and exact subject of the course will therefore not be disclosed and the names of the forum contributors will not be mentioned. Names were only used to define the gender of the posters when possible. When we could not deduce the gender of the author, from names, he or she was categorised as "unknown gender" as were the authors posting under the "anonymous" label.

\section{Results}

Active and self-sustaining participation

Of the total of 625 threads of the course, only 6 were initiated by the staff ( $1 \%$ of the total) and 41 included a reply from the staff (representing a participation in $6.5 \%$ of the total of threads). From the 2,219 posts, $2.8 \%$ of the total was written by the teaching staff. All the remaining content came from the students. Therefore, most of the interaction took place among the participants without intervention from the staff. Posts from the staff mainly informed students about the organisation of the class and the evaluation process. Less often, they also provided administrative information (such as the 'certificate will be issued in pdf format') or responded to a technical question when necessary. Having the staff not contributing substantially could be an advantage, as student participation may increase when discussions are not led by the instructors $[28,29]$. 
Table 2. Contribution to the posts

\begin{tabular}{|c|c|c|}
\hline & Number of posts & $\%$ of the total posts \\
\hline Teaching assistants & 60 & $2.7 \%$ \\
\hline Professor & 2 & $0.1 \%$ \\
\hline Top 10 contributors & 287 & $12.9 \%$ \\
\hline Top contributor & 73 & $3.3 \%$ \\
\hline Second top contributor & 36 & $1.6 \%$ \\
\hline
\end{tabular}

In a previous study analysing another MOOC [56], we observed comparable proportions, with teaching assistants and instructors contributing $2.04 \%$ of all posts. Looking at the top posters (see Table 1, above), we observed that the top 10 posters contributed altogether 287 posts in the selected threads, corresponding to $12.9 \%$ of the analysed posts. The top contributor wrote $3.3 \%$ of the selected posts, and the next in the ranking contributed for $1.6 \%$ only (representing $4.9 \%$ for the top two contributors). These results are very close to our previous research [56] in which the top 2 contributors were the authors of $5 \%$ of all posts and the top 10 contributors authored $7.7 \%$. These numbers are much lower than those from another study that observed that the top 5 contributors were accountable for $43 \%$ of posts for one forum, and of $21 \%$ of posts for another forum [30] (vs. 8.3\% in this research). Compared to these results, we can conclude that this forum provided plenty of opportunity for other participants to express themselves, even if it was supported by a core of regular participants.

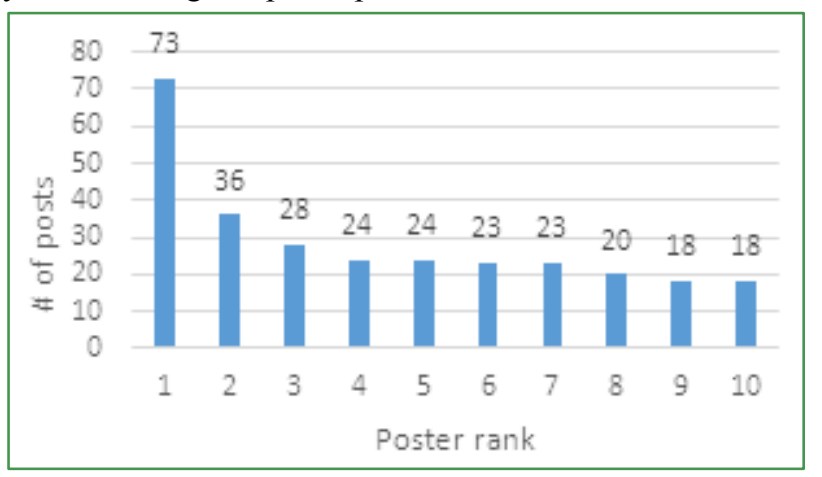

Figure 1. Number of posts for the top 10 contributing participants.

As we did not know the number of participants in this MOOC, we could not compare these observations to the total number of students. The staff communicated only the number of students who took at least one quiz in the previous edition of this same MOOC course, stating that these active students represented about one-fourth of the participants. Students asked for statistics about the number of students, of forum participants and about the completion rates for this specific edition of the course, but the staff did not answer.

\section{Shared culture, norms and values}

Implicitly, all students had to agree with the honour code when registering on the MOOC website. It is very brief and states four principles. Concerning the forums, students have to agree not to 'make solutions to homework, quizzes, exams, projects and other assignments available to anyone else'. Twice, students posted their solutions on the forums. Other participants reacted by reminding them that they have to act according to the honour code.

Therefore, all the contributors seemed to respect a common set of values that were sometimes unwritten but nevertheless established. Appropriate and positive behaviour was acclaimed and inappropriate conduct was sanctioned. A good indicator of common approbation or reprobation was the system of positive and negative votes. When students dared to criticise some aspects of the class, other students reacted by attributing negative votes to the negative comments. For instance, a student said that $\mathrm{s} /$ he thought that "the course was too easy". This opinion received 10 negative votes. The same reaction could be observed to the statement of another student saying that "the blame is all to the organisers of the course". These evaluations and comments acknowledged that there were accepted rules and norms of behaviours; established sanctions (down-votes) were given against what was considered as wrong. Conversely, rewards (positive votes) were granted to what was assessed as correct.

\section{Solidarity, support and reciprocity}

A generally positive feeling seemed to be shared among participants. This might be explained by the observation that students thought this class was amazing and they were grateful for having the opportunity to attend such an elite class for free. We report some of these observations in Table 3 below, as indicators of the prevailing support, solidarity and reciprocity.

Table 3. Solidarity, support and reciprocity indicators

\begin{tabular}{|c|c|c|}
\hline Indicator & Frequency & Verbatim \\
\hline $\begin{array}{l}\text { Statement of positive } \\
\text { appreciation }\end{array}$ & 122 posts & $\begin{array}{c}\text { 'the course was fascinating and challenging' 'it was an amazing world-class } \\
\text { teacher' }\end{array}$ \\
\hline $\begin{array}{l}\text { Gratitude for overcoming } \\
\text { maths challenges }\end{array}$ & 41 posts & $\begin{array}{l}\text { 'I really liked the simple way the teacher explained the complex problems. It was } \\
\text { easy to follow him and understand him' }\end{array}$ \\
\hline Thanks to staff & 92 posts & $\begin{array}{c}\text { 'thank you for this wonderful and insightful class' 'thank you for the excellent } \\
\text { course' }\end{array}$ \\
\hline Help requests & 156 posts & $\begin{array}{l}\text { 'Can anyone help me to resolve this? What do you think?' 'I couldn't figure out } \\
\text { what I'm doing wrong in the quiz' }\end{array}$ \\
\hline Responses to help requests & 271 posts & $\begin{array}{l}\text { 'I think the results are similar to what we saw in the unit on ...' 'Maybe you } \\
\text { should try ...' }\end{array}$ \\
\hline Additional insights & 224 posts & 'an easy way to explain or visualise is to say that' \\
\hline
\end{tabular}


All these indicators show a sense of positive politeness, gratitude and support. The post that received the highest number of positive votes (118) was meant to thank the staff 'for the wonderful class' and for 'their insightful contributions' that went 'beyond the realm of gratitude' and allow a 'deep understanding'. Even when participants were anxious about their competencies in algebra, statistics, programming language and computer science, they felt comfortable enough to express their worries. Moreover, they stated that they were able to overcome these burdens, thanks to the teacher and to their peers. Indeed, classmates were ready and willing to answer questions and help requests. They also provided useful insights and further explanations even when the questions could be considered as answered. Questions were mostly related to the ways of resolving the problems in quizzes and to the understanding of the content and the techniques.

Participants provided new insights on the topics of the course, as well as additional material such as mindmaps of the content or interesting literature references. They also recommended links towards learning material such as Wikipedia pages, sections of the MOOC or YouTube videos. Students considered that what they saw 'in all the forums of this course was an amazing quality of contributions'. These dynamics were important because the students explained that they were not studying within this MOOC environment for the certification, but to learn new knowledge. For instance, a participant stated that $\mathrm{s} / \mathrm{he}$ "was very grateful to all these students who help us with their comments. It was a great initiative to encourage students to help others in learning and sharing.'

These findings are congruent with previous research that showed that students' main motivation in responding to posts was to help other participants [30]. Seeing that others struggle as well, helping each other throughout the learning experience and sharing successes are powerful motivators. This is consistent with previous survey results that demonstrated that $71 \%$ of the 4429 respondents participating in a forum found that their peers' evaluations and comments were helpful (vs 1\% who found them unhelpful) [30].

\section{Criticism, conflict and conflict resolution}

In the forum, participants also criticised what went wrong or what dissatisfied them. Table 4, below, reports the main indicators of such feedback.

Problems of understanding were exacerbated for non-native English speakers because the teacher spoke too fast and indistinctly. Participants complained about the speaking rate and the unclear diction. Subtitles, when available, did not seem to help in most cases as they were only mentioning that some words were inaudible. These hitches made it more difficult for them to learn this new knowledge and to answer quizzes correctly. As a solution, participants started threads in their native language (e.g. Portuguese and Arabic) and formed study groups in foreign languages on Facebook.

Students also struggled with time management and keeping up with deadlines. Some of them pointed out that they had a family to take care of or that they had also to meet deadlines at work. Some participants chose to apply for late submissions even if this meant their results would be discounted by a $10 \%$ penalty for every day late. Participants complained about this policy because they considered the opportunity of 'learning at your own pace' as an important feature of Internet courses. Moreover, it seemed to play an important role in participants' drop-out as 'completing the course was nearly impossible'.

When experiencing trouble with the online system or with the material, some students addressed questions or requests directly to the staff. They also asked the staff to tell them about the class statistics such as the number of participants, completion rate or number of participants in the forum. The teachers told them that they would answer later. But the answer never came ... When the staff was not able to respond to questions, their "way out" was to transfer the request to the MOOC support.

Table 4. Criticism, conflict and conflict resolution indicators

\begin{tabular}{|c|c|c|}
\hline Indicator & Frequency & Verbatim \\
\hline $\begin{array}{c}\text { Misunderstandings due to } \\
\text { language and diction }\end{array}$ & 51 posts & $\begin{array}{c}\text { 'May I request that you slow down just a bit?' 'I am not a native English } \\
\text { speaker, and wording of this question caused problems for me' }\end{array}$ \\
\hline Time and deadline issues & 39 posts & $\begin{array}{c}\text { 'I expected to spend 4-6 hours per week for this course but this kind of } \\
\text { lecture will make me spend 10 hours per week' 'I wish I could do more on the } \\
\text { forums here but barely have time to do so' }\end{array}$ \\
\hline $\begin{array}{c}\text { Potential errors in material } \\
\text { provided and in quizzes }\end{array}$ & 144 posts & $\begin{array}{c}\text { 'please just make sure there is no mistake in the test before I re-take it' 'I } \\
\text { would love you to check that ..., because it seems faulty' }\end{array}$ \\
\hline Mismanagement of the course & 158 posts & $\begin{array}{c}\text { 'There is no due date. What's going on with the dates? It's the 3rd time a date } \\
\text { is wrong' }\end{array}$ \\
\hline Delays on the part of the staff & 28 posts & 'Any news on the grading of the course?' 'How long do we have to wait?' \\
\hline
\end{tabular}


The overall positive evaluation and the generous acclamation of the course did not seem to be affected by the various problems experienced by the participants. Students complained about confusion around deadlines and bad management of the course. For instance, the examination was not available on the predefined date because the staff had unilaterally changed the schedule. Subtitles were not available for some lectures or they were not synchronised with the speech. However, the complaints about errors in lectures, quizzes and examinations did not damage the positive impression of the course or the learning experience. There were, for instance, mistakes in calculations and in the definition of the right answers in quizzes; some correct answers were considered as false and some wrong answers earned marks. Yet, these problems did not tarnish the prestige of the teacher. A student even qualified an error 'as an honest mistake of the teacher'. Participants were patient and politely requested help from the staff.

Finally, at the end of the course, the teachers were not able to send the scores on time. Students worried and asked the teachers about the grading schedule. Some students even suspected that the system might have crashed. The only answer they received was that the grades would be announced soon and certificates would follow. Students joked about the real meaning of 'soon'. Finally, they received their grades two weeks later and students posted celebratory messages on the forum their results and their certificates. A student even harangued classmates by telling them that they had no right to complain as the course was free and the teacher was great.

\section{Self-awareness of the group as an entity}

The forum participants felt part of a group of learners. They talked about groups (195 times) and about the opportunity to split it into smaller groups. They often used the term "we" in their posts (1059 times, vs 5802 for "I").

'Threads created truly builds up camaraderie and group connection'

'This class provides a great opportunity to learn and connect. It's really nice to see such a collective group. '

Some students suggested building study groups to work more efficiently or to continue learning after the course ended. These groups were clearly identified and members had to apply for authorisation.

'To my colleagues: can we form a group to carry on the learning process?'

'I would like to join this group.'

'For the group membership limit, I agree that we should not set a limit.'

Being a member of the group clearly enriched the learning experience.

'I think this group it's a great idea and it can definitively enrich our experience with the course.'

'I'm excited to collaborate with the group.'
Moreover, students were delighted to feel that they were part of a diverse and international group.

'I'm really proud to have the opportunity to share for a while with members of this wonderful international group.'

'I'm glad to meet such a big group of people taking this course from such different places in the world, hope we can share many experiences from our realities.'

'I am so excited when I see how diverse the group is.'

At some point, members of the forum compared their origins. Of course, not all the participants disclosed their citizenship or/and place of residence. However, 325 of them did, naming 412 places. The greater number came from North America (113) and Europe (114), spread over Western Europe (45), Eastern Europe (38), Southeast Europe (11) and the UK (12). For a worldwide distribution, see Table 5 below.

Participants referred also to their education (151 posts) and to their job (103 posts). The most common background was related to the STEM field (148 posts) mainly in computer science (for 32 of them), such as software consultant, computer engineering students or programmer. A fair proportion also worked or studied in the field of communication. Nine of them said that they had or were getting a PhD, 28 a Master's degree and 14 a Bachelor's degree.

Table 5. Worldwide distribution of posters mentioning their origin

\begin{tabular}{|c|c|c|c|c|}
\hline Continent & $\begin{array}{c}\# \\
\text { posters }\end{array}$ & $\%$ & Main countries & $\begin{array}{c}\# \\
\text { posters }\end{array}$ \\
\hline \multirow{3}{*}{ North America } & \multirow{3}{*}{113} & \multirow{3}{*}{27.4} & USA & 82 \\
\hline & & & Canada & 22 \\
\hline & & & Mexico & 9 \\
\hline \multirow{5}{*}{ Europe } & \multirow{5}{*}{114} & \multirow{5}{*}{27.7} & Spain & 22 \\
\hline & & & UK & 12 \\
\hline & & & Germany & 12 \\
\hline & & & Russia & 9 \\
\hline & & & Romania & 7 \\
\hline \multirow{3}{*}{ South America } & \multirow{3}{*}{73} & \multirow{3}{*}{17.7} & Brazil & 41 \\
\hline & & & Colombia & 17 \\
\hline & & & Venezuela & 8 \\
\hline \multirow{4}{*}{ Asia } & \multirow{4}{*}{65} & \multirow{4}{*}{15.8} & India & 24 \\
\hline & & & Indonesia & 8 \\
\hline & & & Pakistan & 7 \\
\hline & & & China & 6 \\
\hline \multirow{2}{*}{ Africa } & \multirow{2}{*}{23} & \multirow{2}{*}{2.9} & South Africa & 5 \\
\hline & & & Nigeria & 5 \\
\hline Oceania & 12 & 2.9 & Australia & 10 \\
\hline Middle East & 12 & 2.9 & Saudi Arabia & 2 \\
\hline
\end{tabular}

Roles, hierarchy, and gender roles

As the content of this course related to science and technology, one could assume, in line with previous 
literature $[43,44]$, that men would be more interested and inclined to study this field. It was noted that 1417 posts could be attributed to men, and 539 to women, leaving 263 as "unknown". These figures indicate that $63.8 \%$ of content was created by men vs $24.3 \%$ written by women $(11.9 \%$ could not be classified).

In frontal traditional (offline) technical learning, as a minority, women might be less willing to ask questions or to participate in discussions since they may have to deal with the dismissive reactions of their male classmates or even sometimes of the instructors [45-48]. We hypothesised that women might adopt different behaviours in online environments: as they do not have to confront face-to-face the patronising attitudes of men when discussing technical matters, women might be more inclined to interact with their classmates. For instance, women might be equally inclined to ask for help when they did not understand the material or to solve problems. Indeed, $30.7 \%$ of people asking for help (158 coded as "ask for help") were female. This proportion is significantly higher than the percentage of female posts ( $\mathrm{p}=0.09$ at significance level $\mathrm{p}<0.1$ ).

We also tested the assumption that women might feel more comfortable at providing technical answers in online environments rather than in traditional classrooms. We analysed the proportion of women participating in the posts assigned to the 'answers to questions' category. We observed that women contributed an inferior percentage in this category of posts $(19.18 \%)$. This proportion is significantly lower than the percentage of men contributing to all selected posts $(\mathrm{p}=0.06)$. These results suggest that women seem to adopt a low profile even when they are online. Therefore, we note the persistence of gender stereotypes and gender roles in the online environment.

Despite the online context, and in accord with previous literature [5,8-10,12], this attitude was unfortunately reinforced in this MOOC by the staff's initiative of creating a Hall of Fame. The teaching assistant put up a list of 11 students who were recognised for having 'posted exemplary scores on quizzes and exams, and for having top reputations in the discussion forum'. This initiative was presumably a 'way to reward those who have been diligently helping their classmates to succeed'. According to the explanation given by the teaching assistant, this ranking was supposed to be based on 'volume activity, up-votes and other feedback'. In the forum, staff assigned a number of points to the main participants, based on the sum of the square root of all the votes received to each post. The criteria used for the ranking, and how they were used, appeared rather confusing. The Hall of Fame list only included male participants. Women congratulated the rewarded students, until a woman challenged the absence of female names. Strangely enough, according to our analysis, there were four women among the top 10 contributors. Most of their posts were up-voted and one of them even received the highest score in terms of up-votes (118 votes). According to the points awarded by the staff, there should have been three women among the top 11 forum students. Some women seemed to match the level of men regarding activity volume and up-votes; the reasons why female classmates were absent from this Hall of Fame remains unclear. Some of the women seemed surprised by this result and posted comments to question this ranking, asking:

'Where are the women? I'd like to know what proportion of the class is female. Perhaps there are not many of us ...'.

'I notice that women are under-represented - maybe absent altogether? From this list. Women - we need to participate fully in order to get the most out of this amazing opportunity'.

After female voices were heard, the teaching assistant announced that 'since our last post we have a few new names to add to the Hall of Fame'. There were, this time, three female names among the five additions to the list. The Hall of Fame clearly established a hierarchy. By excluding women, in its initial version, it reinforced gender differences and exacerbated the stereotype that women are less competent in scientific and technical matters.

\section{Conclusion and future work}

According to Herring's criteria [20], the forum related to the studied MOOC fits the definition of a real community [33, 34]. The learners felt this sense of community as well. In particular, we could observe that participants had a common connection with the main activity, which was learning this field of knowledge. They further discussed the provided content and brought additional material. There was some socialisation process as well, as people acted (by posting) and interacted (by responding to the posts). Participants offered the opportunity to join study groups and learners applied to team up. Moral responsibility was demonstrated through the help provided by members and answers given to questions, that seemed to be considered as a duty to the community and as a norm of appropriate conduct. The Hall of Fame revealed a hierarchy; staff explained the processes for advancement within the hierarchy even though these processes appeared rather obscure.

This research shows that gender roles related to STEM classes were replicated online. Similarly to what happens in traditional STEM courses, females participated less than males and, when they did, their participation was more about asking questions and looking for help from others. They seemed less prone to reply to questions and provide content support to other posters, whatever the reasons. This might reflect the stereotype that female students are less good at technical matters and cannot be of any help. Our research also observed that, as in traditional STEM classes [45-48] the teaching staff discredited the female activities, confirming that online behaviour follows the same logic as the offline pattern.

Forum participants, in a connectivist approach, created knowledge together by requesting help, answering questions, discussing concepts and techniques, suggesting applications and additional learning material. They demonstrated a 
common interest in the field and a strong sense of support. The common values and norms of the community seemed so strong that they did not allow any divergent opinion about the quality of the class and the competence of the teacher. We can wonder whether people with a conflicting opinion preferred either to remain silent about their true beliefs or not to take part in the forum activities at all.

As a MOOC class, taking place on one of the major MOOC platforms, this course was commonly considered as an XMOOC, built on the traditional information transmission format [11]. However, our analysis showed that forums play a crucial role in the learning experience. The community was able to learn and produce knowledge collaboratively. By counting the number of posts per participant, we observed that not all the MOOC forums necessarily include an overwhelming presence of a few top posters who tend to "own" the conversation. On the contrary, some MOOC forums, such as the one analysed in this research, seem to demonstrate a rather discreet presence of the few top posters, leaving enough room for all members to feel welcome to participate in the conversation. These findings reinforce the role of forums as a socialising and cross-learning experience platform. The teaching staff had a role of facilitator in the forum, and members became knowledge co-creators. Students had the opportunity of learning in and from the network. Therefore, it becomes apparent that the forum has become the connectivist part of the behaviourist MOOC. What was once deemed to be so clearly distinct starts blurring, at least for the members of the forum.

Therefore, we suggest adding a new category for MOOCs when forums add a connectivist part to the behaviourist transfer of knowledge. We propose naming them 'mMOOC', for 'mixed MOOCs' that are neither xMOOC (information passed from the instructor to learners [3]) nor cMOOC (exchange of information among participants based on connectivist approaches [13]). mMOOCs combine characteristics of both xMOOCs and cMOOCs by providing video lectures given by instructors, accompanied by information exchange and knowledge co-creation through forums led by the participants. This fits Dubosson et al.'s [56] definition of mMOOC as 'Massive Open Online Courses, which include a mix of formal lectures, passing information in the classic form, and of connectivist exchanges among course participants, with limited course staff intervention, i.e. when less than $10 \%$ of all posts are due to staff'.

This raises the question of whether there is only one specific kind of mMOOC participants, or whether there are different types of students who choose to take part in MOOCs in different ways. Therefore, in the mMOOC environment, the connectivist and individualistic approaches might be either combined or chosen individually. Some students might choose not to participate in the forum, but to learn by watching the videos and evaluating their understanding through quizzes (individualistic - xMOOC option). Others might prefer to focus on participating in forums and to skip videos or watch just some parts of them (connectivist - cMOOC). Finally, students might opt for a combination of individualistic and connectivist approaches by using all the offered activities (mix of approaches mMOOC). The mMOOC category might offer the advantage of meeting the needs of different user profiles. New research may focus on the connectivist and individualistic approaches of MOOC's participants and may confirm the existence of different participant segments, based on different needs and behaviours.

Further research should be conducted in order to study all these issues in greater depth, and to link them with learning outcomes and completion rates. It might also help to identify the drivers and indicators of a well-functioning MOOC.

\section{REFERENCES}

[1] S. Mak, R. Williams, J. Mackness. Blogs and Forums as Communication and Learning Tools in a MOOC, $7^{\text {th }}$ International Conference Networked Learning, University of Lancaster, 275-285, 2010.

[2] G. Siemens. Massive Open Online Courses: Innovation in Education. In R. Mc Greal, W. Kinuthia, S. Marshall, (Eds), Open Educational Resources: Innovation, Research and Practice, Commonwealth of Learning and Athabasca University, Vancouver, 5-15, 2013.

[3] T. Clarke. The advance of the MOOCs (massive open online courses). The impending globalization of business education?, Education+ Training, Vol. 55, No. 4/5, 403-413, 2013.

[4] J. Warren, S. Rixner, J. Greiner, S. Wong. Facilitating human interaction in an online programming course, $45^{\text {th }}$ ACM technical symposium on Computer science education, Atlanta, 665-670, 2014

[5] R. Williams, R. Karousou, J. Mackness. Emergent learning and learning ecologies in web 2.0, The International Review of Research in Open and Distance Learning, Vol. 12, No. 3, 39-59, 2011.

[6] S. Mitra, P. Arora. Afterthoughts, British Journal of Educational Technology, Vol. 41, 703-705, 2010.

[7] S. De Freitas, G. Conole. Learners experiences: how pervasive and integrative tools influence expectations of study. In R. Sharpe et al. (Eds.) Rethinking learning for a digital age: how learners shape their own experiences, Routledge, London, 15-30, 2010. Online available from http://sgi.cueltd.net/publications/papers/Learner_experience_ chapter_v7.pdf

[8] A. McAuley, B. Stewart, G. Siemens, D. Cormier. The MOOC Model for Digital Practice, 2010. Online available from:

http://www.davecormier.com/edblog/wp-content/uploads/M OOC Final.pdf

[9] C. O. Rodriguez. MOOCs and the AI-Stanford like courses: Two successful and distinct course formats for Massive Open Online Courses, European Journal of Open, Distance and E-Learning, 2012. Online available from: http://files.eric.ed.gov/fulltext/EJ982976.pdf

[10] T. Bates. What's right and what's wrong about Coursera-style, 2012. Online available from: 
http://www.tonybates.ca/2012/08/05/whats-right-and-whatswrong-about-coursera-style-moocs/

[11] P. Hill. Online educational delivery models: A descriptive view, Educause Review, Nov/Dec, 84-86, 2014. Online available from: http://er.dut.ac.za/bitstream/handle/123456789/56/Hill 2012 _Online_Educational_Delivery_Models.pdf?sequence=1

[12] J. Daniel. Making sense of MOOCs: Musings in a maze of myth, paradox and possibility, Journal of Interactive Media in Education, Vol. 3, 2012. Online available from: http://jime.open.ac.uk/articles/10.5334/2012-18/

[13] G. Siemens, S. Downes. Connectivism \& connective knowledge, 2008. Online available from: https://oerknowledgecloud.org/sites/oerknowledgecloud.org/ files/Connective_Knowledge-19May2012.pdf

[14] C. Bremer, D. Weiss. How to analyze participation in a (c)MOOC?, $5^{\text {th }}$ International Conference on Education and New Learning Technologies, EDULEARN13, Barcelona, 992-1002, 2013.

[15] T.R. Liyanagunawardena, A.A. Adams, S.A. Williams. MOOCs: A systematic study of the published literature 2008 2012, The International Review of Research in Open and Distance Learning, Vol. 14, No. 3, 202-227, 2013.

[16] P. Hill. Four Barriers that MOOCs must overcome to build a sustainable model, 2012. Online available from: $\mathrm{http}: / /$ mfeldstein.com/four-barriers-that-moocs-must-overco me-to-become-sustainable-model/

[17] G. Siemens. MOOCs are really a platform, ELearnspace, 2012. Online available from:

http://www.elarnspace.org/blog/2012/07/25/moocs-are-reall y-a-platform/

[18] W.B. Gudykunst. Cultural variability in communication an introduction, Communication research, Vol. 24, No. 4, 327-348, 1997

[19] G. Hofstede. Culture's consequences: International differences in work-related values, Sage Publications, Inc., 1984.

[20] S.C. Herring. Computer-mediated Discourse Analysis, An approach to researching online behavior. In S. Barab, R. Kling, J. Gray. Designing for virtual communities in the service of learning, Cambridge University Press, 2004.

[21] H. Rheingold. The Virtual Community: Homesteading on the electronic frontier, MIT Press, Cambridge, Massachusetts, 1993.

[22] J. Preece, D. Maloney-Krichmar, C. Abras. History of online communities. In K. Christiansen, D. Levinson (Eds.). Encyclopedia of Community: From Village to virtual world, Thousands Oaks, California, 1023-1027, 2003.

[23] L.M. Angelino, F.K. Williams, D. Natvig. Strategies to engage online students and reduce attrition rates, The Journal of Educators Online, Vol. 4, No. 2, 2007.

[24] J. Preece. Online communities: Designing usability and supporting sociability, John Wiley \& Sons, Inc., 2000.

[25] B.A. Frey, S.W. Alman. Applying adult learning theory to the online classroom, New horizons in adult education, Vol. 17, No. 1, 4-12, 2003.
[26] A. P. Rovai. Building sense of community at a distance, The International Review of Research in Open and Distributed Learning, Vol. 3, No. 1, 1-9, 2002.

[27] F. Ke, K. Xie. Online discussion design on adult students' learning perceptions and patterns of online interactions, $9^{\text {th }}$ International Conference on Computer supported collaborative learning, Vol. 1, 219-226, 2009.

[28] L. Cifuentes, K.L. Murphy, R. Segur, S. Kodali. Design considerations for computer conferences, Journal of Research on Computing in Education, Vol. 30, No. 2, 177-201, 1997.

[29] A.P. Rovai, Facilitating online discussions effectively, The Internet and Higher Education, Vol. 10, No. 1, 77-88, 2007.

[30] D. Coetzee, A. Fox, M.A. Hearst, B. Hartmann. Should your MOOC forum use a reputation system?, $17^{\text {th }}$ ACM conference on Computer supportive cooperative work \& social computing, 1176-1186, 2014.

[31] D.R. Garrison, T. Anderson, W. Archer. Critical inquiry in a text-based environment: Computer conferencing in higher education, The Internet and Higher Education, Vol. 2, No. 2, 87-105, 1999.

[32] A.P. Rovai. Development of an instrument to measure classroom community, The Internet and Higher Education, Vol. 5, No. 3, $197-211,2002$

[33] S.L. Jarvenpaa, D. E. Leidner. Communication and trust in global virtual teams, Journal of Computer-Mediated Communication, Vol. 3, No. 4, 1998.

[34] H.T. Tsai, R.P. Bagozzi. Contribution behavior in virtual communities: Cognitive, emotional and social influences, Mis Quarterly, Vol. 38, No. 1, 143-163, 2014.

[35] A. Anderson, D. Huttenlocher, J. Kleinberg, J. Leskovec. Engaging with massive online courses, $23^{\text {rd }}$ International Conference on World wide web, ACM, Seoul, 687-697, 2014.

[36] K.E. Dooley, L.E. Wickersham. Distraction, domination, and disconnection in whole-class online discussions, The Quarterly Review of Distance Education, Vol. 8, No. 1, 1-8, 2007.

[37] L.A. Moller, D. Harvey, M. Downs, V. Godshalk. Identifying factors that affect learning community development and performance in asynchronous distance education, Quarterly Review of Distance Education, Vol. 1, No. 4, 293-305, 2000.

[38] J. Davis, M. Graff. Performance in e-learning: online participation and student grades, British Journal of Educational Technology, Vol. 36, No. 4, 657-663, 2005.

[39] S. Rayyan, D.T. Seaton, J. Belcher, D.E. Pritchard, I. Chuang. Participation and performance in $8.02 \mathrm{x}$ electricity and magnetism: The first physics MOOC from MITx, preprint arXiv:1310.3173, 2013. Online available from: http://arxiv.org/pdf/1310.3173.pdf

[40] T. Lewin. Universities abroad join partnerships on the Web, The New York Times, Vol. 21, 2013. Online available from: http://www.nytimes.com/2013/02/21/education/universitiesabroad-join-mooc-course-projects.html

[41] C. Alario-Hoyos, M. Pérez-Sanagustín, C. Delgado-Kloos, M. Muñoz-Organero, A. Rodríguez-de-las-Heras. Analysing the impact of built-in and external social tools in a MOOC on educational technologies. In Scaling up learning for sustained impact, Springer, Berlin, 5-18, 2013. 
[42] P. Adamopoulos. What makes a great MOOC? An interdisciplinary analysis of student retention in online courses, $34^{\text {th }}$ International Conference on Information Systems, Milan, 2013.

[43] M.G. Jones, A. Howe, M.J. Rua. Gender differences in students' experiences, interests, and attitudes toward science and scientists, Science education, Vol. 84, No. 2, 180-192, 2000.

[44] S.S. Starobin, F.S. Laanan. Broadening female participation in science, technology, engineering, and mathematics: Experiences at community colleges, New directions for community colleges, Vol. 142, 37-46, 2008.

[45] T.A. Greenfield. Gender- and grade-level differences in science interest and participation, Science Education, Vol. 81, No.3, 259-276, 1997.

[46] M. Sadker, D. Sadker. Failing at Fairness: How America's Schools Cheat Girls, Simon and Schuster, New York, 2010.

[47] H.C. She. Interaction between different gender students and their teacher in junior high school biology classes, National Science Council, Republic of China, Part D: Mathematics, Science, and Technology Education, Vol. 8, 16-21, 1998.

[48] H.C. She. Students' knowledge construction in small groups in the seventh grade biology laboratory: Verbal communication and physical engagement, International Journal of Science Education, Vol. 21, No. 10, 1051-1066, 1999.

[49] M. Wang, C. Sierra, T. Folger. Building a dynamic online learning community among adult learners, Educational Media International, Vol. 40, No. 1-2, 49-62, 2003.

[50] K.D. Blum. Gender differences in asynchronous learning in higher education learning styles, participation barriers and communication patterns, Journal of Asynchronous Learning Networks, Vol. 3, No. 1, 1999.

[51] A.P. Rovai. Building classroom community at a distance: A case study, Educational Technology Research and Development, Vol. 49, No. 4, 33-48, 2001.
[52] J.B. Arbaugh. An exploratory study of the effects of gender on learning and class participation in an internet-based MBA course, Management Learning, Vol. 31, No. 4, 503-519, 2000 .

[53] R.F. Kizilcec, C. Piech, E. Schneider. Deconstructing disengagement: Analyzing learner subpopulations in massive open online courses, Third International Conference on Learning analytics and knowledge, ACM, 170-179, 2013.

[54] P.J. Guo, K. Reinecke. Demographic differences in how students navigate through MOOCs, First ACM conference on Learning@scale conference, 21-30,2014.

[55] C.M. Steele, S.J. Spencer, J. Aronson. Contending with group image: The psychology of stereotype and social identity threat, Advances in experimental social psychology, Vol. 34, 379-440, 2002.

[56] M. Dubosson, S. Emad, A. Broillet, C. Kampf. Video and Course Content discussion on Massive Open Online Courses: An exploratory Research, IEEE Professional Communication Conference (IPCC), Pittsburgh, 1-9, 2014.

[57] J.A. Sandlin. Netnography as a consumer education research tool, International Journal of Consumer Studies, Vol. 31, 288-294, 2007.

[58] R.V. Kozinets. The field behind the screen: Using netnography for marketing research in online communities, Journal of Marketing Research, Vol. 39, 61-72, 2002.

[59] M. Hammersley, P. Atkinson. Ethnography: Principles in Practice, $3^{\text {rd }}$ edition, Routledge, New York, 2007.

[60] J. Scott, G. Marshall. A Dictionary of Sociology, Oxford University Press, 1998.

[61] Y.S. Lincoln, E.G. Guba. Naturalistic Inquiry, Sage, Beverley Hills, 1985. Document resume online available from: http://files.eric.ed.gov/fulltext/ED297007.pdf

[62] S.A. King. Researching Internet communities: Proposed ethical guidelines for the reporting of results, The Information Society: An International Journal, Vol. 12, No. 2, 119-128, 1996. 